\title{
Transport behaviors of humic acid, kaolin and kaolin-humic acid compound colloids on naphthalene in floating islands with biofilmed fillers
}

\author{
Sheng Yu' ${ }^{1}$ Bang-yu $\mathrm{Li}^{1} \cdot \mathrm{Yi}-\mathrm{hu} \mathrm{Chen}^{1}$
}

Received: 23 March 2017 / Accepted: 30 October 2019 / Published online: 28 December 2019

(c) The Author(s) 2019

\begin{abstract}
As one of the persistent organic pollutants, the investigations of naphthalene transports with humic acid, kaolin and kaolin-humic acid compound colloids by passing through the floating islands with biofilmed filler matrix pores were checked out. Naphthalene was easily captured onto the biofilmed fillers while it was passing through the floating islands with the filling percentages of 0.0 to 60.0 by absorbing bigger contaminated colloids, reflecting that the naphthalene concentrations in influents were, respectively, decreased from 200 to $57 \mu \mathrm{g} \mathrm{L}^{-1}$ for the humic acid colloids, to $32 \mu \mathrm{g} \mathrm{L}^{-1}$ for the kaolin colloids and to $13 \mu \mathrm{g} \mathrm{L}^{-1}$ for the kaolin-humic acid compound colloids. With the filling percentages of 60.0 to 80.0 , the naphthalene concentrations in effluents were maintained at $57 \pm 2 \mu \mathrm{g} \mathrm{L}{ }^{-1}$ for the humic acid colloids, at $32 \pm 3 \mu \mathrm{g} \mathrm{L}^{-1}$ for the kaolin colloids and at $13 \pm 3 \mu \mathrm{g} \mathrm{L}^{-1}$ for the kaolin-humic acid compound colloids, respectively. The naphthalene distribution amounts on the biofilmed fillers were, respectively, from 213 to $96 \mathrm{ng} \mathrm{m}^{-1}$ for the humic acid colloids, from 274 to $96 \mathrm{ng} \mathrm{m}^{-1}$ for the kaolin colloids and from 340 to $83 \mathrm{ng} \mathrm{m}^{-1}$ for the kaolin-humic acid compound colloids. Thus, the biofilmed fillers in the floating islands could decrease the naphthalene concentrations by the captures of the humic acid, kaolin and kaolin-humic acid compound colloids to make the contaminated colloid concentrations reduced and promote the water qualities.
\end{abstract}

Keywords Naphthalene $\cdot$ Colloid $\cdot$ Floating island $\cdot$ Biofilmed filler

\section{Introduction}

Considered as the ring hydrocarbons, polycyclic aromatic hydrocarbons (PAHs) are formally defined as lacking further branching substituent off the ring structures (Cheng et al. 2012; Rao et al. 2014; Vane et al. 2014; Ozaki et al. 2015). PAHs could be accumulated and present of a serious risk without transformation on ecosystems and human health because of their biological toxicity in environment ( $\mathrm{Gu}$ et al. 2011; Lv et al. 2014; Vane et al. 2014; Knappenberger et al. 2015). For one of the exogenous hydrophobic organic contaminants and being evaluated as the possibly carcinogenic, naphthalene of a fused pair of benzene rings is the class of hydrophobic and persistent organic environmental pollutant

Sheng Yu

yus@jssvc.edu.cn

1 Lab of Environment and Analysis, Suzhou Vocational University, International Education Park, 106 Zhi-neng Avenue, Suzhou 215104, Jiangsu, People's Republic of China due to its frequent occurrence in environment with its significantly toxic and carcinogenic properties (Rao et al. 2014; Saleh and Gupta 2014; Vane et al. 2014; Tcaciuc et al. 2015; Ziegler et al. 2106). Mostly derived from coal tar processes, coal/petroleum cracking and volcanic eruptions, naphthalene also would be involved to illustrate transport behaviors on its characteristics of mixing into polymers, not chemically bound to the plastic and particularly susceptible to separating or leaking into the environment (Sponza and Oztekin 2011; Knappenberger et al. 2015).

Considering its carcinogen and resistant to physical, chemical or biological degradation properties of low vapor pressure $\left(13.1 \mathrm{~Pa} / 25^{\circ} \mathrm{C}\right)$ and low aqueous solubility (31.7 $\mathrm{mg} \mathrm{L}^{-1} / 25^{\circ} \mathrm{C}$ ) and high lipophilic and hydrophobic properties by nature ( $\log K_{\mathrm{OW}}=3.4$ and $\log K_{\mathrm{OC}}=2.6$ ), the remediation effects of naphthalene by the fillers of the ecological floating islands were checked. Unlike other soluble contaminants moving freely in water, naphthalene might have various restrictions on the transport of insoluble matters (like colloids) by both capture and sorption mechanism (Gaffney et al. 1996; Gu et al. 2011; Lv et al. 2014). 
Moreover, the colloids in waters could provide an important and effective pathway if the insoluble contaminates in question adsorb strongly and irreversibly in suspension for quite long times (Yu et al. 2013; Vane et al. 2014).

Waters cover $71 \%$ of the Earth's surface and are vital for all known forms of life. In the most recent national report on water qualities, water pollution is a major global problem which requires ongoing evaluation and revision of water resource policy at all levels from international down to individual aquifers and wells. As one of the solidification/ stabilization methods, remediation (in-situ and ex-situ) is to utilize chemically or biochemically reactive formulations to transform water contaminants to non-hazardous or less-hazardous ones (de Lima et al. 2014; Li et al. 2016). Considered as a cheap, efficient and potential technology, floating island is one of the highlighted researches in the world for water remediation. Floating islands have been adopted to help purify waters worldwide due to providing habitats for certain animals, shoreline erosion protection and the enhancement of landscape features (Mahajan and Sud 2012). Thus, the floating island is widely used to solve severe problems of river and lake pollutions with the advantages of simple operation, no secondary pollution and high reliability. Based on the contaminant removals, floating island for water purification is generally best choice to remediate river and lake waters (Yao et al. 2011; de Lima et al. 2014; Avio et al. 2017; Jabli et al. 2017).

Nevertheless, the naphthalene transport behaviors in floating island in waters by the different kinds of colloids have not been thoroughly imaged and detailed, especially due to occurring of the very complex water and floating island interactions (Marchal et al. 2013; Dathe et al. 2014). The main aims were to remove naphthalene as the exogenous organic pollutant in water environment when the floating islands with biofilmed fillers were used primarily to carry out their effects to provide theoretical foundation and technological support for the water remediation.

\section{Materials and methods}

\section{Chemicals and instrument}

Naphthalene (Alfa Aesar ${ }^{\circledR}, 97 \%$ ) and n-hexane (Alfa Aesar ${ }^{\circledR}$, 99.7\%) were brought from Johnson Matthey in the USA. The concentrations of the suspended colloids $(\leq 0.1 \mu \mathrm{m})$ in the natural waters gathered in Suzhou $\left(31^{\circ} 15^{\prime} \mathrm{N}, 120^{\circ}\right.$ $35^{\prime} \mathrm{E}$ ) were $20.0 \pm 0.7 \mathrm{mg} \mathrm{L}^{-1}$ by being filtrated with 0.1 $\mu \mathrm{m}$ membrane and centrifuged under the condition of the 5000 -g gravity acceleration for $30 \mathrm{~min}$. With the processes above, the concentrations of the suspended colloids in supernatants were less than $0.02 \mathrm{mg} \mathrm{L}^{-1}$. The experimental waters were restored in darkness and detailed in Table 1,
Table 1 Properties of the experimental waters

\begin{tabular}{|c|c|}
\hline Properties & Values \\
\hline Temperature $\left({ }^{\circ} \mathrm{C}\right)$ & $25 \pm 2$ \\
\hline $\mathrm{pH}$ & $7.2 \pm 0.1$ \\
\hline Dissolved oxygen $\left(\mathrm{mg} \mathrm{L}^{-1}\right)$ & $7.8 \pm 0.7$ \\
\hline Conductivity $\left(\mu \mathrm{S} \mathrm{cm}^{-1}\right)$ & $88.2 \pm 3.7$ \\
\hline \multicolumn{2}{|l|}{ Hardness $(\mathrm{mg} / \mathrm{L}, \mathrm{CaO})$} \\
\hline Carbonate hardness & $24.9 \pm 1.6$ \\
\hline Non-carbonate hardness & $2.3 \pm 1.1$ \\
\hline \multicolumn{2}{|l|}{ Main ions $(m g / L)$} \\
\hline $\mathrm{Na}^{+}$ & $77.4 \pm 3.1$ \\
\hline $\mathrm{Ca}^{2+}$ & $8.7 \pm 0.4$ \\
\hline $\mathrm{Mg}^{2+}$ & $4.2 \pm 1.1$ \\
\hline $\mathrm{Fe}^{3+}$ & $0.5 \pm 0.1$ \\
\hline $\mathrm{Al}^{3+}$ & $0.1 \pm 0.1$ \\
\hline $\mathrm{Cl}^{-}$ & $30.6 \pm 0.9$ \\
\hline $\mathrm{HCO}_{3}^{-}$ & $21.7 \pm 0.8$ \\
\hline $\mathrm{SO}_{4}{ }^{2-}$ & $8.7 \pm 1.3$ \\
\hline Transparency (m) & $0.6 \pm 0.2$ \\
\hline Chrominance $\left({ }^{\circ}\right)$ & $6 \pm 2$ \\
\hline Colloid concentration $\left(\mathrm{mg} \mathrm{L}^{-1}\right)$ & $20 \pm 0.7$ \\
\hline Suspended colloid concentration in supernatant $\left(\mathrm{mg} \mathrm{L}^{-1}\right)$ & $\leq 0.02$ \\
\hline Colloid size $(\mu \mathrm{m})$ & $\leq 0.1$ \\
\hline Soluble matter $\left(\mathrm{mg} \mathrm{L}^{-1}\right)$ & $3.4 \pm 0.2$ \\
\hline
\end{tabular}

Table 2 Measures of the experimental fillers of the floating islands

\begin{tabular}{ll}
\hline Measures & Values \\
\hline Major material & Polypropylene \\
$\mathrm{pH}$ & $6.9 \pm 0.2$ \\
Specific area $\left(\mathrm{m}^{2} \mathrm{~m}^{-1}\right)$ & $46.3 \pm 3.8$ \\
Fiber diameter $(\mu \mathrm{m})$ & $0.10 \pm 0.02$ \\
Appearance size $(\mathrm{cm})$ & $5.1 \pm 0.2$ \\
Porosity $(\%)$ & $98.5 \pm 0.3$ \\
Design density $\left(\mathrm{kg} \mathrm{m}^{-1}\right)$ & $1.17 \pm 0.14$ \\
\hline
\end{tabular}

while the concentrations of the soluble organic matters were of $3.4 \pm 0.2 \mathrm{mg} \mathrm{L}^{-1}$ and the values of the concerned metal ions of $\mathrm{Fe}^{3+}$ and $\mathrm{Al}^{3+}$ were of $0.5 \pm 0.1 \mathrm{mg} \mathrm{L}^{-1}$ and $0.1 \pm 0.1 \mathrm{mg} \mathrm{L}^{-1}$ without any $\mathrm{pH}$ adjustment. Besides, the measures of the experimental fillers as the important components of the floating islands are shown in Table 2 as well.

\section{Experiment method}

Kaolin was added into humic acid solution with $0.1 \mathrm{~mol} \mathrm{~L}^{-1}$ sodium hydroxide, and then $0.1 \mathrm{~mol} \mathrm{~L}^{-1}$ hydrochloric acid was adjusted to settle down the kaolin-humic acid compounded matters (rinsed thrice and airdried at $105 \pm 2{ }^{\circ} \mathrm{C}$ for $120 \mathrm{~min}$ ) which were grinded and 
screened $(\leq 0.1 \mu \mathrm{m})$ to form the kaolin-humic acid compounded colloids $\left(m_{\text {kaolin }} / m_{\text {humic acid }}=1: 1\right)$. The grinded and screened $(\leq 0.1 \mu \mathrm{m})$ processes of the kaolin-humic acid compounded colloids were carried out on the kaolin colloids and the humic acid colloids as well. Naphthalene were evenly and rapidly sprayed to the humic acid, kaolin and kaolin-humic acid compounded colloids to the contents of $10.0 \mu \mathrm{g} \mathrm{g}^{-1} \mathrm{D}$.W. and air-dried in darkness for $120 \mathrm{~h}$ until n-hexanes were completely evaporated (comparison of contrast groups and the experimental ones). Thereafter, the contaminated colloids were aged and stored for $120 \mathrm{~h}$ at $4{ }^{\circ} \mathrm{C}$ in refrigerator. By hydraulic mixing for $120 \mathrm{~min}$, the three different contaminated colloids were added in the experimental waters as the influents to increase the concentrations of the colloid concentrations of $20.0 \pm 0.4 \mathrm{~m} \mathrm{~L}^{-1}$ as the naphthalene pollutant resource of the concentration of $200.0 \pm 1.5 \mathrm{ng} \mathrm{L}^{-1}$.

The glass devices shown in Fig. 1 ( $L 60 \mathrm{~cm}$ in length $\times W 20 \mathrm{~cm}$ in width $\times D 20 \mathrm{~cm}$ including $5 \mathrm{~cm}$ excessive height in depth) were cleaned by $\mathrm{HNO}_{3}$ of $3 \%(\mathrm{~m} / \mathrm{m})$, rinsed with distilled water and oven-dried at $105{ }^{\circ} \mathrm{C}$ for at least $2 \mathrm{~h}$. Those glass devices were horizontally set by two pieces of $10-\mu \mathrm{m}$ porous glass membranes $(W 20 \mathrm{~cm} \times D 20 \mathrm{~cm})$ to divide into the reactor $(L$
$50 \mathrm{~cm} \times W 20 \mathrm{~cm} \times D 20 \mathrm{~cm}$ ), the influent tank $(L 5 \mathrm{~cm} \times W$ $20 \times D 20 \mathrm{~cm})$ and effluent tank $(L 5 \mathrm{~cm} \times W 20 \mathrm{~cm} \times D$ $20 \mathrm{~cm}$ ). The floating islands were made by one piece of foam $(L 50 \mathrm{~cm} \times W 20 \mathrm{~cm})$, and several fillers $(D 15 \mathrm{~cm})$ were fixed under the foam where the filling ratios were from the minimum percentage of 0.0 to the maximum percentage of 80.0 . The biomass $\left(12.1 \pm 0.3 \mathrm{~g} \mathrm{~m}(\text { filler })^{-1}\right)$ were cultured for 30.0 days by the natural waters without any manual intervention. The floating islands were placed in the reactors $(L 50 \mathrm{~cm} \times W 20 \mathrm{~cm} \times D 20 \mathrm{~cm})$. The sterile islands were fixed by the same fillers as control and the filling percentages of $0.0-80.0$ as well. Remediation behaviors of floating islands on the humic acid, kaolin and kaolin-humic acid compounded colloids were occurred by feeding the reactors with continuous influents $\left(25 \pm 1^{\circ} \mathrm{C}\right)$ of the flow rate of 30.01 day $^{-1}$ by the gravity force actions. The experimental characteristics of the floating islands are analyzed in Table 3.

The influents and effluents from the test reactors and sterile ones were collected and pretreated for preparation determination of the colloid concentrations with $0.1-\mu \mathrm{m}$ membrane and centrifuged under the condition of $5000 \mathrm{~g}$ for $30 \mathrm{~min}$. Naphthalene concentrations were checked after determining the concentrations of the colloids by being
Fig. 1 Experimental device of the transport behaviors of naphthalene by different colloids
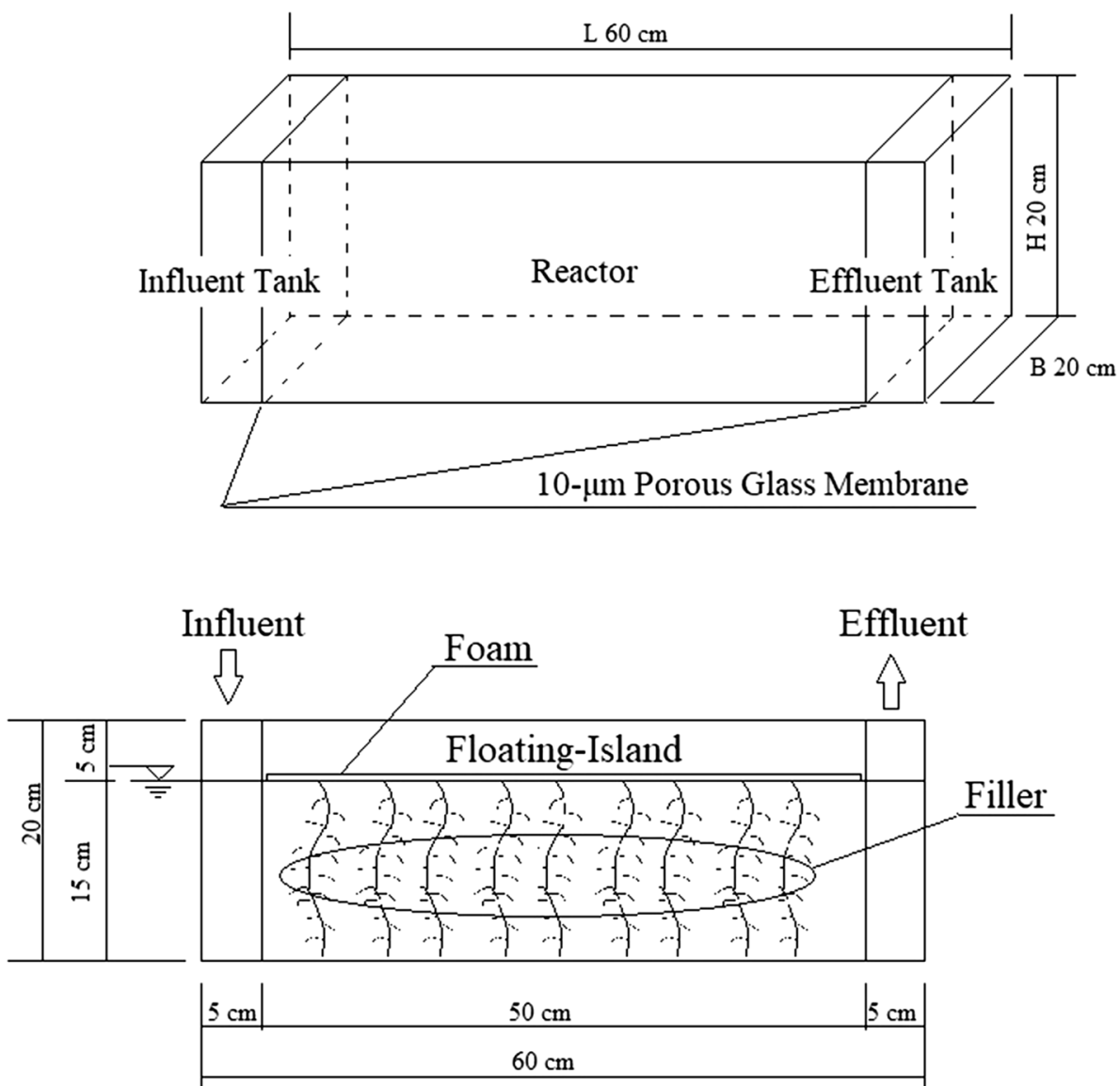
Table 3 Characteristics of the floating islands on removals of naphthalene

\begin{tabular}{llll}
\hline Characteristics & Test island & WP2 & WP3 \\
\cline { 2 - 3 } & WP1 & Kaolin colloid & Compounded colloid \\
Colloid type & Humic acid colloid & \\
Filling percentage of filler (\%) & $20.0-80.0$ & 12 \\
Hydraulic retention time (h) & $3.4 \pm 0.2$ & \\
Concentration of soluble organic matters in influent $\left(\mathrm{mg} \mathrm{L}^{-1}\right)$ & $0.6 \pm 0.1$ & \\
Concentration of metal ions in influent $\left(\mathrm{mg} \mathrm{L}^{-1}\right)$ & 30.0 & \\
Flow of influent $\left(\mathrm{L} \mathrm{day}^{-1}\right)$ & $100(20.0 \%)-25(80.0 \%)$ & $\mathrm{ND}$ \\
Ratio of liquid and filler $\left(\mathrm{L} \mathrm{m}^{-1}\right)$ & & \\
Original concentration of naphthalene in waters $\left(\mathrm{ng} \mathrm{L}^{-1}\right)$ & &
\end{tabular}

extracted thrice by $\mathrm{n}$-hexane $(\mathrm{m} / \mathrm{v}=1: 3$ for colloids and $v / v=1: 2$ for supernatants) with ultrasound $(60 \mathrm{kHz}, 300 \mathrm{~W})$, the recovery rates of which were from 98 to $103 \%$ for colloids and from 97 to $102 \%$ for supernatants, respectively. The supplied influent volumes into the reactors were recorded to calculate the reaction volume numbers of floating islands every 10 days. At the end of the 180-day experiments, the three floating islands (respectively, named as WP1 of the humic acid colloids, WP2 of the kaolin colloids and WP3 of the kaolin-humic acid compounded colloids) were to study the amount distributions of naphthalene under the experimental conditions at the filling percentages of 60.0. The fillers from the floating islands were destructed into 5 pieces $(L 10 \mathrm{~cm} \times W 20 \mathrm{~cm} \times D 15 \mathrm{~cm})$. The destructed fillers were air-dried, smashed $(\leq 1 \mu \mathrm{m})$ and extracted twice with ultrasound $(60 \mathrm{kHz}, 300 \mathrm{~W})$ by $\mathrm{n}$-hexane $(\mathrm{m} / \mathrm{v}=1: 3)$. The n-hexane solutions were purified by $\mathrm{NaCl}$ of $10 \%(\mathrm{~m} / \mathrm{m})$, extracted with Supelclean LC-C18 tubes after dehydration and evaporated to $1 \mathrm{ml}$ for HPLC determination (Urbain et al. 1993).

\section{Naphthalene detection}

The identification and quantification of naphthalene were performed using a Shimadzu Essential LC-16 HPLC with the SPD-16 UV detector. The C18 column (WondaSil C18-WR, $5 \mu \mathrm{m}$ particles, $150 \times 4.6 \mathrm{~mm}$, Shimadzu, Japan) was used to separate naphthalene with the temperature of $30{ }^{\circ} \mathrm{C}$. The methyl alcohol and water (85:15, HPLC) were

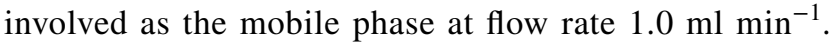
Then $10 \mu \mathrm{l}$ was injected as well, and the ultraviolet detection wavelength $\lambda$ was made at $357 \mathrm{~nm}$. Within each batch of the samples, one blank control, the absence of a tissue sample in the extraction vessel was then subjected to the whole experimental procedure to determine any analytical contamination. The concentrations of the humic acid, kaolin and kaolin-humic acid compounded colloids in influents and effluents were measured with the same processes described above. The concentrations of soluble organic matters and metal ions were determined by $\mathrm{K}_{2} \mathrm{Cr}_{2} \mathrm{O}_{7}-\mathrm{H}_{2} \mathrm{SO}_{4} / \mathrm{Ag}_{2} \mathrm{SO}_{4}$ reagents at $\lambda_{440 \pm 20}$ and ICP-MS by standard reagents.

\section{Results and discussion}

\section{Naphthalene removals by fillers of the floating islands with colloids}

Colloids in natural waters might be to provide an only efficient pathway for carrying and moving strongly and irreversibly adsorbing and remaining insoluble high lipophilic and hydrophobic contaminates in suspension over long times (Alem et al. 2015; Tcaciuc et al. 2015). The processes herein are usually to be identified as "colloid-facilitated transport" providing an efficient way for contaminants bound onto colloids presently and sustainably suspending in waters for a quite long time (Du et al. 2013; Dathe et al. 2014). It meant that colloids might affect the naphthalene removals in waters by being bound rather large amounts as very complex part of fine particles in water environment (Knappenberger et al. 2015; Avio et al. 2017). Although there are many different colloids in waters, the main colloids could probably be focused on the humic acid, kaolin and kaolin-humic acid compounded colloids which are involved in this test (Alem et al. 2015).

Owing to its low aqueous solubility $\left(31.7 \mathrm{mg} \mathrm{L}^{-1} / 25^{\circ} \mathrm{C}\right)$ and high lipophilic and hydrophobic property by nature $\left(\log K_{\mathrm{OW}}=3.4\right.$ and $\left.\log K_{\mathrm{OC}}=2.6\right)$, the naphthalene removals were dominated, respectively, by decreasing the humic, kaolin and humic-kaolin compounded colloid concentrations (WP1, WP2 and WP3 in Fig. 2). Moreover, the values of the naphthalene concentrations in supernatants from filtration and acceleration were below the detection limits $\left(\leq 5.6 \mathrm{ng} \mathrm{L}^{-1}\right)$. The naphthalene removal values were decreased with the increasing filling percentages of 20.0 to 60.0 of the fillers. With the filling percentages of 60.0 to 80.0 of the fillers, the removal values of the naphthalene were not obviously revealed at the level of $p<0.05$. The 


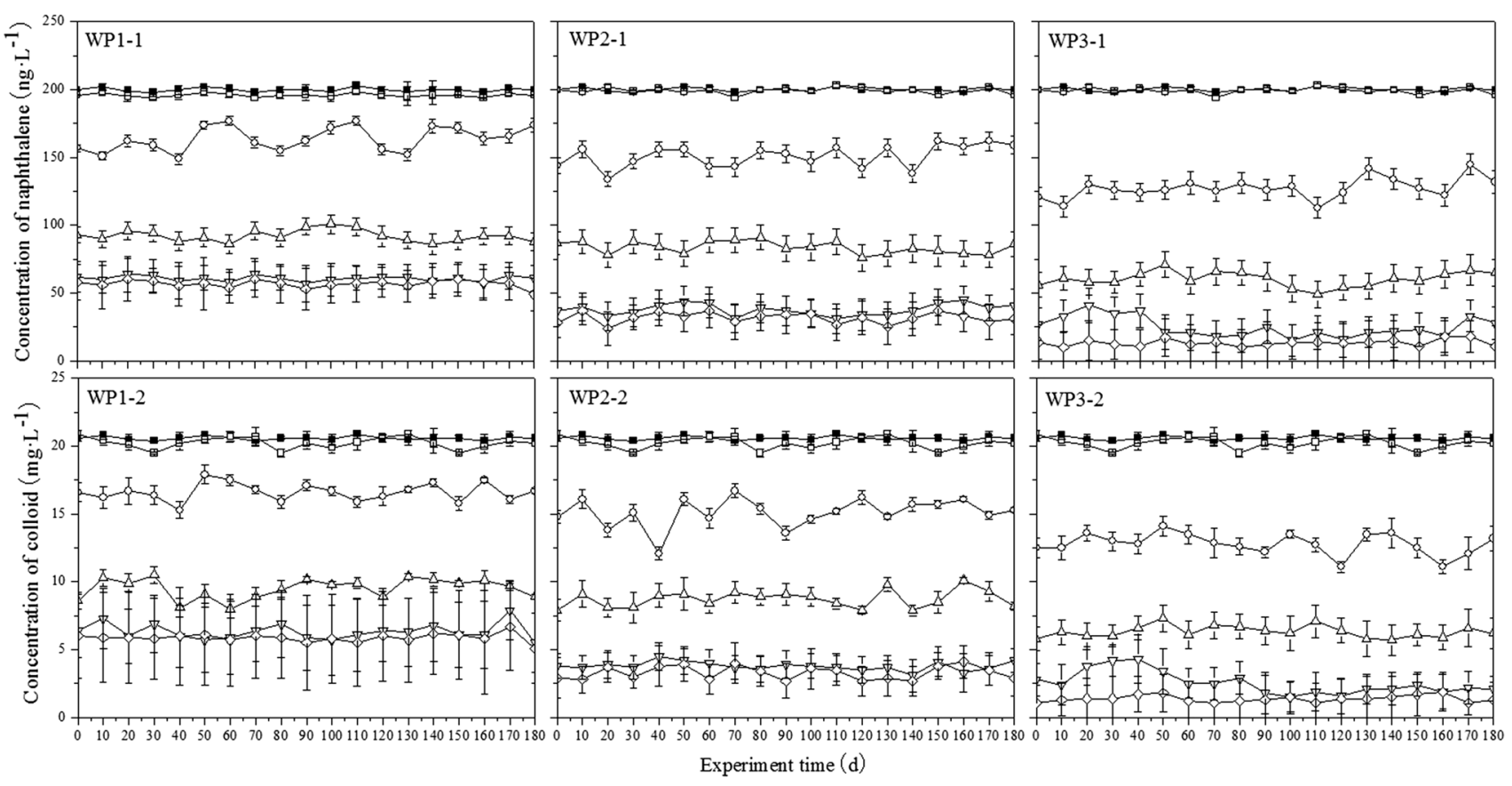

Fig. 2 Removal effects of the fillers on naphthalene by colloids in waters. Concentrations of naphthalene on humic acid colloids (WP1-1), kaolin colloids (WP2-1) and kaolin-humic acid compounded colloids (WP3-1) in influents (—-) and the different effluents were gathered with the different filling percentages of

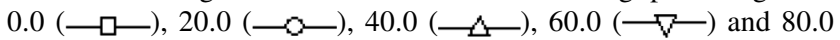

naphthalene concentrations in effluents were decreased from 200 to $57 \mu \mathrm{g} \mathrm{L}^{-1}$ (WP1-1), to $32 \mu \mathrm{g} \mathrm{L}^{-1}$ (WP2-1) and to $13 \mu \mathrm{g} \mathrm{L}^{-1}$ (WP3-1) within the filling percentages of 0.0 to 60.0 , respectively. Within the filling percentages of 60.0 to 80.0, the naphthalene concentrations in effluents were maintained at $57 \pm 2 \mu \mathrm{g} \mathrm{L}^{-1}$ (WP1-1), at $32 \pm 3 \mu \mathrm{g} \mathrm{L}^{-1}$ (WP21) and at $13 \pm 3 \mu \mathrm{g} \mathrm{L}^{-1}$ (WP3-1), respectively. It could be explained that the contaminated colloid concentrations in effluents were decreasing from 20.0 to $5.9 \mathrm{mg} \mathrm{L}^{-1}$ (WP1-2), to $3.3 \mathrm{mg} \mathrm{L}^{-1}$ (WP2-2) and to $1.4 \mathrm{mg} \mathrm{L}^{-1}$ (WP3-2) within the filling percentages of 20.0 to 60.0 of the fillers, respectively. At the range of the filling percentages of 60.0 to 80.0 of the fillers, the contaminated colloids concentrations in effluents were maintained at $5.8 \pm 0.4 \mathrm{mg} \mathrm{L}^{-1}$ (WP1-2), at $3.1 \pm 0.3 \mathrm{mg} \mathrm{L}^{-1}$ (WP1-2) and at $1.3 \pm 3 \mathrm{mg} \mathrm{L}^{-1}$ (WP3-2), respectively. The bigger particles including the humic acid, kaolin and kaolin-humic acid compounded colloids might be more easily captured onto the filler surfaces with the increasing absorption abilities of the biomass to decrease the naphthalene concentrations comparison of the smaller ones which would be precipitated onto the filler surfaces where the coagulation and precipitation of the particles were carried out (Tarasevich et al. 2013). Based on the processes above, the naphthalene concentrations were reduced rapidly with the increasing values of the filler surface areas $(\prec-)$ of fillers under the conditions of colloid concentrations in influents of $20.0 \mathrm{mg} \mathrm{L}^{-1}$, respectively. Besides, the contaminated humic acid colloids (WP1-2), contaminated kaolin colloids (WP2-2) and kaolin-humic acid contaminated compounded colloids (WP3-2) were measured as well to analysis the behaviors of naphthalene in waters

for trapping the bigger contaminated colloids in waters. By contrast, the smaller contaminated colloids would be more freely suspended in waters for long time and distance without gathering effects to pass through the fillers matrix and raise the contaminated colloid concentrations as well as naphthalene in effluents.

Focused again on WP1, WP2 and WP3 in Fig. 2, the naphthalene concentrations of the humic, kaolin and humic-kaolin compounded colloids in effluents at the same filling percentages were significant different $(p<0.05)$. The highest and lowest naphthalene concentrations along with contaminated colloids in effluents were, respectively, occurred in WP1 and WP3 of Fig. 2. The humic acid colloids with the properties of hydrophilicity and hydrophobicity for forming and stabilizing the more colloids in natural waters were to present the highest concentrations of naphthalene and colloids in effluents (Stevenson 1982; Marchal et al. 2013; Yu et al. 2013; Rao et al. 2014). The kaolin colloids could border and absorb some soluble organic matters and metal ions (like $\mathrm{Fe}^{3+}$ and $\mathrm{Al}^{3+}$ ) certainly keeping the kaolin colloids suspended at the low concentrations in natural waters (Simarro et al. 2011; Field et al. 2016). When the metal-ion-absorbed kaolin colloids went across the fillers of the floating islands, the kaolin colloids would be intercepted on the biofilmed filler surfaces with the help of $\mathrm{Fe}^{3+}$ 
and $\mathrm{Al}^{3+}$ usually used as the coagulants of the colloids in natural waters (Arab et al. 2014; Ozaki et al. 2015; Field et al. 2016). By rights, the removal amounts of the kaolin-humic acid compound colloids would be the oppositely highest in those three different contaminated colloids. It was checked that the kaolin-humic acid compound colloids with the properties of the adsorption of humic acid colloids and self-coagulation of the kaolin colloids both of which were propitious to concentration of the contaminated colloids to the much higher levels for making the bigger particles and then precipitate them out of the waters to decrease the kaolin-humic acid compound colloids concentrations in effluents (Alem et al. 2015; Yu et al. 2015; Field et al. 2016). Thus, the phenomena in WP1, WP2 and WP3 of Fig. 2 were taken place with the reasons of the interactions between the filling percentages of the fillers and the different contaminated colloids in natural waters to affect the naphthalene removal behaviors.

\section{Naphthalene distributions on the fillers of the floating islands with colloids}

As the organic carbon sources, humic acids were in present for the capabilities to lead the concerned processes of the controlling naphthalene behaviors (Jaradat et al. 2009; Mahajan and Sud 2012; Jung et al. 2014). Meanwhile, kaolin covered with lots of negative charges would perform certain polarities to absorb some metal ions in natural waters. When the absorbed amounts of the metal ions were less than those of the cation capacity of kaolin, they would play the efficient roles of division of kaolin particles for easier stabilization in waters. In addition, the composite kaolin-humic acid compounded colloids were fused the characteristics of the humic acid and kaolin on colloids and to facilitate the naphthalene translocation in waters as well (Arab et al. 2014; Tcaciuc et al. 2015; Field et al. 2016). Based on the behaviors of the humic acid, kaolin and kaolin-humic acid compounded colloids, the naphthalene removal behaviors were seriously done with the contaminated colloid removal behaviors in floating islands by acquisition and interception of fillers, meaning that all the suspended contaminated colloids would comparatively charge the naphthalene transports to move into far distances in waters compared with the soluble organic matters and metal ions which would not outstandingly change the naphthalene solubility (Sponza and Oztekin 2011; Avio et al. 2017).

Furthermore, the experimental fillers were made by polypropylene (PP) whose structure was monotonous without any special functional groups except for methyl groups to affect any useful interactions for the perspective of the binding forces of the humic acid colloid-PP, kaolin colloid-PP and kaolin-humic acid compounded colloid-PP. The biomass films with plenty of negative charges on the surfaces would reject the same charge particles (Yao et al. 2011). It was emerged that the humic acid colloids and kaolin colloids were not able to approach the biomass nearly to be caught by the fillers with the help of the loose structures and properties of the humic acid colloids and kaolin colloids by nature detailed above. The capture processes of the humic acid colloids and kaolin colloids were made by the inertia forces, being supposed that the interception and distribution of the colloids and naphthalene were much the similar especially in the lengths of $30.0 \mathrm{~cm}$ to $50.0 \mathrm{~cm}$ of the floating islands. For the kaolin-humic acid compounded colloids, the structures and properties were more inseparable and strongly adsorptive. They could rapidly be gathered by the fillers to express that the interception amounts of naphthalene were much higher in the first $0.0 \mathrm{~cm}$ to $10.0 \mathrm{~cm}$ lengths (about $50 \%$ of the total interception amounts) of the floating islands. The sum amounts of the rest parts in the lengths of $10.0 \mathrm{~cm}$ to $50.0 \mathrm{~cm}$ of the floating islands were about $50 \%$ of the total interception amounts by the inertia and adsorption forces. It was placed that the naphthalene removal behaviors were significantly dominated by catching the suspended colloids with the biofilmed fillers in Fig. 2. An outcome was that adsorption and interception of naphthalene in far distances did carry out during the naphthalene through the floating islands with the biofilmed fillers. The humic acid colloids, kaolin colloids and kaolin-humic acid compound colloids were able to go in and through the filler pores and appear in the effluents. In those processes, the biofilmed fillers were to trap the naphthalene to, respectively, decrease the concentrations of naphthalene and colloids both of which were positively correlated in the effluents (Yao et al. 2011; Alem et al. 2015). In brief, the naphthalene removal behaviors through the filler matrix were due to the reduction of the contaminated colloid concentrations.

Although the interception amounts of naphthalene were varied by in the floating islands, the ratio values of the calculated naphthalene amounts in the influent tanks, effluent tanks and floating islands (named as S) to original naphthalene amounts in the influents by counting the experimental water volumes (named as I) were no less than $99.8 \%$

Table 4 Interception amounts of naphthalene in influent tanks, effluent tanks and 0.0-50.0 cm-length floating islands

\begin{tabular}{lrrr}
\hline & \multicolumn{3}{l}{ Floating island } \\
\cline { 2 - 4 } & \multicolumn{1}{l}{ WP1 } & WP2 & \multicolumn{1}{l}{ WP3 } \\
\hline Influent tank (ng) & $300.3 \pm 2.3$ & $300.2 \pm 1.8$ & $300.5 \pm 2.1$ \\
0.0-50.0-cm island (ng) & $618.9 \pm 7.5$ & $666.9 \pm 7.1$ & $679.7 \pm 6.6$ \\
Effluent tank (ng) & $158.9 \pm 4.3$ & $112.1 \pm 3.8$ & $99.7 \pm 4.8$ \\
Sum (ng) & $1078.1 \pm 8.9$ & $1079.2 \pm 8.3$ & $1079.9 \pm 8.4$ \\
Initial addition (ng) & $1080.2 \pm 3.2$ & $1080.7 \pm 2.4$ & $1080.2 \pm 2.7$ \\
Sum/initial addition (\%) & $99.8 \pm 0.4$ & $99.9 \pm 0.7$ & $99.8 \pm 0.6$ \\
\hline
\end{tabular}


in Table 4. It was indicated that naphthalene in complexes would undergo both the chemo- and bio-chemo-degradation and evaporation into the atmosphere because of the values of the $\log K_{\mathrm{OW}}$ and $\log K_{\mathrm{OC}}$ of naphthalene by nature (Yu et al. 2010; Simarro et al. 2011; Rao et al. 2014).

\section{Capture behaviors of floating island on both naphthalene and every colloid}

It was known that the results of colloid transport behaviors in waters were not much clearer due to the complex constituents and structures (Yu et al. 2010; Alem et al. 2015). Naphthalene behaviors in waters were less detailed because of its properties by nature. Furthermore, the few reports of the hybrid transports of naphthalene and every colloid were figured out (Avio et al. 2017; Jabli et al. 2017). Consequently, it was carefully analyzed and contrasted the transport behaviors between naphthalene and every colloid (humic acid colloid, kaolin colloid and kaolin-humic acid colloid).

Although the big contaminated particles would be much more easily trapped by the biofilmed fillers while small contaminated ones passing through the filler matrix (Jaradat et al. 2009; Knappenberger et al. 2015), the calculated ratio values of the trapped colloid amounts and decreased naphthalene amounts were from 99.6 to $101.2 \%$ compared with Figs. 2 and 3. It was meant that naphthalene was not redistributed under the conditions of the three different colloid transport processes. The calculated naphthalene losses in our work could be negligible, signifying that the involved naphthalene in this work would be almost absorbed on the three different colloids as well as those with the help of its properties by nature (Sponza and Oztekin 2011; Saleh and Gupta 2014). By the outcomes discussed above, the distributions of the different colloids with the naphthalene are imaged in Fig. 4. Besides, the biofilmed fillers were covered los of active functional groups (like $-\mathrm{OH},-\mathrm{COOH},-\mathrm{NH}_{2}$, and so on) which might provide several connections to play a more important role of aggregating either big contaminated particles in the first $0-\mathrm{cm}$ to $30-\mathrm{cm}$ areas in floating islands or small even fine contaminated ones in the rest $30-\mathrm{cm}$ to $50-\mathrm{cm}$ areas in floating island. The first $0-\mathrm{cm}$ to $30-\mathrm{cm}$ areas in floating islands could be subdivided into the $0-\mathrm{cm}$ to $20-\mathrm{cm}$ areas where the significant changes of both the colloids and the naphthalene were appeared and paid much close attention, whereas the variables of those in $20-\mathrm{cm}$ to $30-\mathrm{cm}$ areas were not obvious. With the help of both humic acid supplying the organic carbons and kaolin engendering the hydration shells of silicon dioxide as well as absorbing the coagulating metal ions of $\mathrm{Fe}^{3+}$ and $\mathrm{Al}^{3+}$ (Yu et al. 2010; Jung et al. 2014), the biomass on fillers would be rapidly catch the kaolin-humic acid compounded colloids to decrease the naphthalene concentrations in waters at present of the first $0-\mathrm{cm}$ to $20-\mathrm{cm}$ areas in floating islands (kaolin-humic acid compounded colloids in Fig. 4). The kaolin colloids with the comprehensive effects of the hydration shells of silicon dioxide and metal ions of $\mathrm{Fe}^{3+}$ and $\mathrm{Al}^{3+}$ might probably semi-anti-captured by producing negative charges to push away the particles by the force of repulsive interactions (Sponza and Oztekin 2011; Saleh and Gupta 2014; Tcaciuc et al. 2015). The separated amounts of the kaolin colloids with naphthalene in the first $0-\mathrm{cm}$ to $20-\mathrm{cm}$ areas in floating islands were much less than those of the kaolin-humic acid compounded colloids (kaolin colloids in Fig. 4). In view of the partial microorganism metabolic products being ionized in natural waters, humic acid colloids could exist and move freely for a long time, reflecting that naphthalene-polluted humic acid colloids could transport freely either (Yu et al. 2015; Ziegler et al. 2106). That was the reason why the intercepted contaminated humic acid colloids with naphthalene in the first $0-\mathrm{cm}$ to $20-\mathrm{cm}$ areas in floating islands were the least.
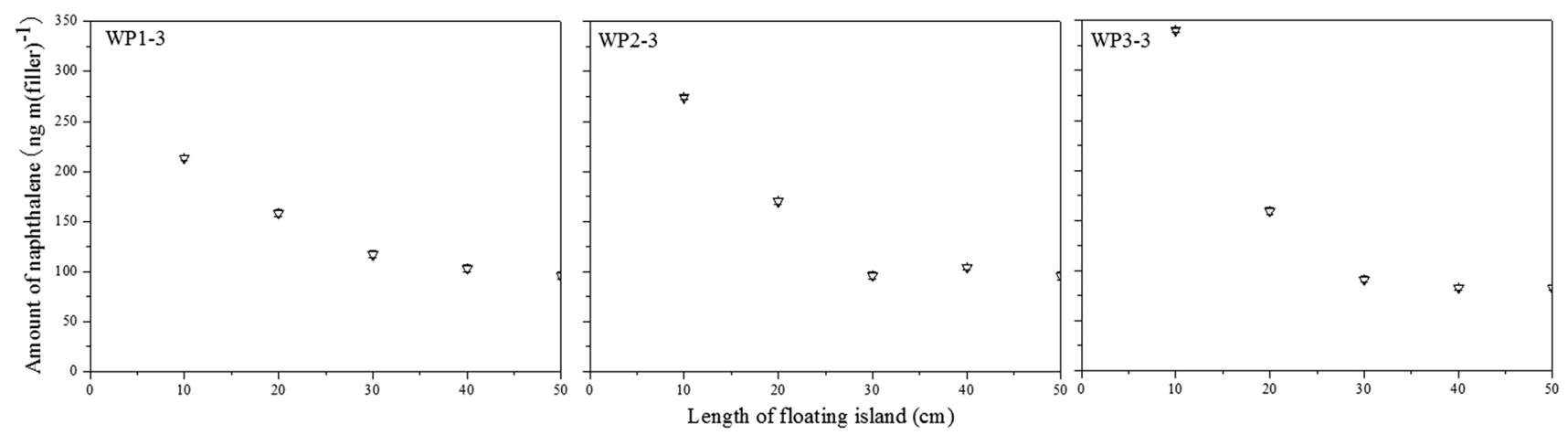

Fig. 3 Distribution amounts of naphthalene on the fillers with different colloids. Distribution amounts of naphthalene with humic acid colloids (WP1-3), kaolin colloids (WP2-3) and kaolin-humic acid compounded colloids (WP3-3) were checked in different lengths of
$0.0-50.0 \mathrm{~cm} \mathrm{( \longrightarrow -)} \mathrm{of} \mathrm{the} \mathrm{floating} \mathrm{islands} \mathrm{fixed} \mathrm{with} \mathrm{filling} \mathrm{per-}$ centage of 60 of fillers under the conditions of colloid concentrations in influents of $20.0 \mathrm{mg} \mathrm{L}^{-1}$, respectively 
Fig. 4 Transport behaviors of humic acid, kaolin and kaolinhumic acid compounded colloids on naphthalene in floating islands

\section{Contaminated Colloids}

Humic Acid Colloids

Kaolin Colloids

Kaolin-Humic Acid Compounded Colloids

\section{Conclusions}

The transport behaviors of the floating islands on naphthalene in waters were figured out in this work. It was illustrated that both soluble organic matters and metal ions were not to change the removal values while the naphthalene removal behaviors were mainly charged by the processes of the humic acid, kaolin and kaolin-humic acid compounded colloids decreased concentrations with the increases of filling percentages of the fillers due to the interception and adsorption of the biofilmed fillers. The effects of the biofilmed fillers were to absorb naphthalene to decrease the passages of contaminated colloids through the filler matrix pores. The average interception amounts of naphthalene were the highest by the kaolin-humic acid compounded colloids comparison
Floating-Island

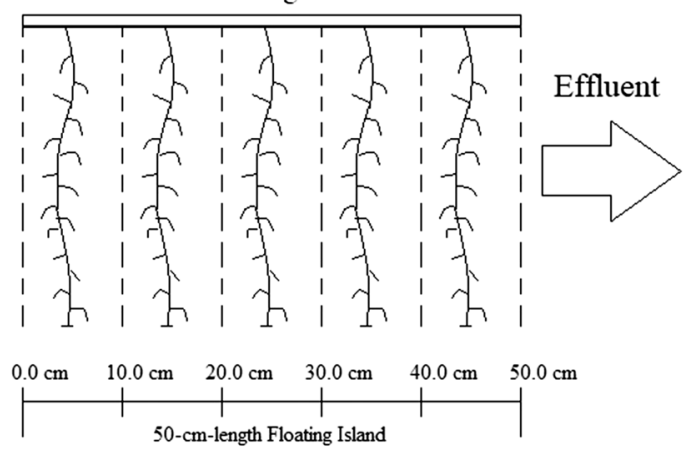

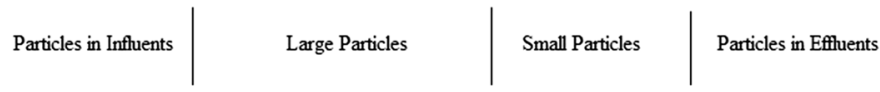

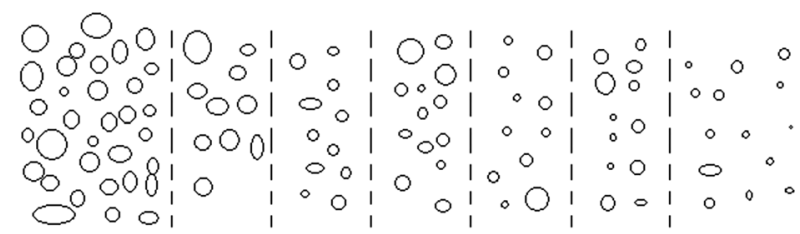

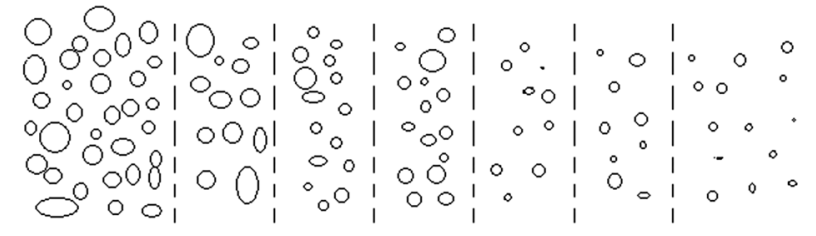

of those by the humic acid or kaolin colloids. The conclusions herein offered advancing outcomes that naphthalene concentrations could be reduced rapidly through the filler matrix and settled down in the floating islands by catching colloids with the help of the structures and properties of the humic acid, kaolin and humic acid-kaolin compounded colloids. Thus, the capture capabilities of biofilmed fillers could directly decrease the amounts of naphthalene in the effluents to promote the qualities of the polluted natural waters.

Acknowledgements This work is funded by Industry Prospective Application Research (Industry) Guidance Plan of Suzhou Science and Technology Bureau, Science Foundation of Suzhou Vocational University (SVU2015YY02) and "Qing-Lan Project" Foundation of Suzhou Vocational University. We also thank C. Liu and L. Yu for technical assistance. 
Open Access This article is licensed under a Creative Commons Attribution 4.0 International License, which permits use, sharing, adaptation, distribution and reproduction in any medium or format, as long as you give appropriate credit to the original author(s) and the source, provide a link to the Creative Commons licence, and indicate if changes were made. The images or other third party material in this article are included in the article's Creative Commons licence, unless indicated otherwise in a credit line to the material. If material is not included in the article's Creative Commons licence and your intended use is not permitted by statutory regulation or exceeds the permitted use, you will need to obtain permission directly from the copyright holder. To view a copy of this licence, visit http://creativecommons.org/licenses/by/4.0/.

\section{References}

Alem A, Ahfir ND, Elkawafi A et al (2015) Hydraulic operating conditions and particle concentration effects on physical clogging of a porous medium. Transp Porous Media 106:303-321

Arab D, Pourafshary P, Ayatollahi S et al (2014) Remediation of colloid-facilitated contaminant transport in saturated porous media treated by nanoparticles. Int J Environ Sci Technol 11:207-216

Avio CG, Cardelli LR, Gorbi S et al (2017) Microplastics pollution after the removal of the Costa Concordia wreck: first evidences from a biomonitoring case study. Environ Pollut 227:207-214

Cheng JO, Ko FC, Li JJ et al (2012) Concentrations of polycyclic aromatic hydrocarbon in the surface sediments from inter-tidal areas of Kenting coast, Taiwan. Environ Monit Assess 184:3481-3490

Dathe A, Zevi Y, Richards BK et al (2014) Functional models for colloid retention in porous media at the triple line. Environ Sci Pollut Res 21:9067-9080

de Lima IR, dos Santos LU, Tosetto MS et al (2014) Urban water reuse: microbial pathogens control by direct filtration and ultraviolet disinfection. J Water Health 12:465-473

Du YC, Shen CY, Zhang HY et al (2013) Effects of flow velocity and nonionic surfactant on colloid straining in saturated porous media under unfavorable conditions. Transp Porous Media 98:193-208

Field G, Tavrisov G, Brown C et al (2016) Particle filters to estimate properties of confined aquifers. Water Resour Manag 9:3175-3189

Gaffney JS, Marley NA, Clark SB (1996) Humic and fulvic acidsisolation, structure, and environmental role. American Chemical Society, Washington, p 308

Gu L, Zhu NW, Wang L et al (2011) Combined humic acid adsorption and enhanced Fenton processes for the treatment of naphthalene dye intermediate wastewater. J Hazard Mater 198:232-240

Jabli M, Saleh TA, Sebeia N et al (2017) Dimethyl diallyl ammonium chloride and diallylamin co-polymer modified bio-film derived from palm dates for the adsorption of dyes. Sci Rep 7:1444-1448

Jaradat AQ, Grimberg SJ, Holsen TM (2009) Colloid transport through natural filter media. J Environ Eng 135:544-550

Jung B, O'Carroll D, Sleep B (2014) The influence of humic acid and clay content on the transport of polymer-coated iron nanoparticles through sand. Sci Total Environ 496:155-164

Knappenberger T, Aramrak S, Flury M (2015) Transport of barrel and spherical shaped colloids in unsaturated porous media. J Contam Hydrol 180:69-79

Li M, Raleve D, Chen WL et al (2016) Field evaluation of intensive compost application on Cd fractionation and phytoavailability in a mining-contaminated soil. Environ Geochem Health 38:1193-1201
Lv JP, Xu J, Guo CS et al (2014) Spatial and temporal distribution of polycyclic aromatic hydrocarbons (PAHs) in surface water from Liaohe river basin, northeast China. Environ Sci Pollut Res 21:7088-7096

Mahajan G, Sud D (2012) Modified agricultural waste biomass with enhanced responsive properties for metal-ion remediation: a green approach. Appl Water Sci 2:299-308

Marchal G, Smith KE, Rein A et al (2013) Comparing the desorption and biodegradation of low concentrations of phenanthrene sorbed to activated carbon, biochar and compost. Chemosphere 90:1767-1778

Ozaki N, Takamura T, Kojima K et al (2015) Loading and removal of PAHs in a wastewater treatment plant in a separated sewer system. Water Res 80:337-345

Rao KJ, Chaudhuri RG, Paria S (2014) Naphthalene degradation in the presence of natural-synthetic surfactants mixture by mixed bacterial cultures. J Environ Chem Eng 2:826-831

Saleh TA, Gupta VK (2014) Processing methods, characteristics and adsorption behavior of tire derived carbons: a review. Adv Colloid Interface Sci 211:93-101

Simarro R, González N, Bautista LF et al (2011) Optimisation of key abiotic factors of PAH (naphthalene, phenanthrene and anthracene) biodegradation process by a bacterial consortium. Water Air Soil Pollut 217:365-374

Sponza DT, Oztekin R (2011) Removals of some hydrophobic polyaromatic hydrocarbons (PAHs) and daphnia magna acute toxicity in a petrochemical industry wastewater with ultrasound in IzmirTurkey. Sep Purif Technol 77:301-311

Stevenson FJ (1982) Humus chemistry: genesis, composition, reactions. Wiley, New York, p 432

Tarasevich YI, Dolenko SA, Trifonova MY et al (2013) Association and colloid-chemical properties of humic acids in aqueous solutions. Colloid J 75:207-213

Tcaciuc AP, Apell JN, Gschwend PM (2015) Modeling the transport of organic chemicals between polyethylene passive samplers and water in finite and infinite bath conditions. Environ Toxicol Chem 34:2739-2749

Urbain V, Block JC, Manem J (1993) Bioflocculation in activated sludge: an analytical approach. Water Res 27:829-838

Vane CH, Kim AW, Beriro DJ et al (2014) Polycyclic aromatic hydrocarbons (PAH) and polychlorinated biphenyls (PCB) in urban soils of Greater London, UK. Appl Geochem 51:303-314

Yao K, Song S, Zhang ZM et al (2011) Vegetation characteristics and water purification by artificial floating island. Afr J Biotech 10:19119-19125

Yu S, Zou P, Zhu W et al (2010) Effects of humic acids and microorganisms on decabromodiphenyl ether, 4,4'-dibromodiphenyl ether and anthracene transportation in soil. Sci China Chem 53:950-968

Yu S, Zou P, Zhu W et al (2013) Effects of humic acid and Tween-80 on behavior of decabromodiphenyl ether in soil columns. Environ Earth Sci 69:1523-1528

Yu S, Li BY, Chen YH (2015) Influences of humic acid and fulvic acid on horizontal leaching behavior of anthracene in soil barriers. Environ Sci Pollut Res 22:20114-20120

Ziegler P, Sree KS, Appenroth KJ (2016) Duckweeds for water remediation and toxicity testing. Toxicol Environ Chem 98:1127-1154

Publisher's Note Springer Nature remains neutral with regard to jurisdictional claims in published maps and institutional affiliations. 